\title{
UN ANÁLISIS AL CONTENIDO DE TRES PROYECTOS DE REFORMA CONSTITUCIONAL
}

\section{AN ANALYSIS TO THE CONTENT OF THREE PROJECTS OF CONSTITUTIONAL REFORM}

\author{
Carlos Hakansson ${ }^{1}$ \\ Docente \\ Universidad de Piura \\ carlos.hakansson@udep.pe
}

Perú

\section{SUMARIO}

- El camino trazado por el proyecto de ley y sus desfiladeros

- Los antecedentes históricos y constitucionales de la Ley de Reforma Constitucional N. ${ }^{\circ}$ 2001/2012-IC

- El contenido del proyecto de ley de reforma

- El proyecto de ley 267/2016-CR que propone incorporar de modo expreso el reconocimiento de un Estado laico

- El proyecto de ley 1740/2017-CR que propone restituir el sistema bicameral

- A modo de conclusión: El estado de los expedientes $\mathrm{X}$

\section{RESUMEN}

El artículo comenta tres proyectos de ley de reforma constitucional presentados al Congreso como son: el proyecto de ley de reforma, el proyecto de ley 267/2016-CR que propone incorporar de modo expreso el reconocimiento de un Estado laico, y el proyecto de ley 1740/2017-CR que propone restituir el sistema bicameral. Asimismo, analiza su contenido y acierto en la tarea de realizar una reforma política.

\section{ABSTRACT}

The article comments on three bills of constitutional reform submitted to Congress such as: the bill of reform, the bill 267/2016$\mathrm{CR}$ that proposes to expressly incorporate the recognition of a secular state, and the draft law 1740/2017-CR that proposes to restore the bicameral system. It also analyzes its content and its success in the task of carrying out a political reform.

\section{PALABRAS CLAVE}

Proyectos de ley, reforma constitucional, bicameralismo, Estado laico

\section{KEYWORDS}

Parliament's bills, constitutional amendments, bicameralism, lay state

\section{EL CAMINO TRAZADO POR \\ EL PROYECTO DE LEY Y SUS DESFILADEROS}

El proyecto de Ley de Reforma Constitucional (ley N. ${ }^{\circ}$ 2001/2012-IC), publicado el 23 de marzo de 2013, contiene disposiciones que revelan una estrategia para retornar a la Constitución de 1979, pero incorporando algunas instituciones de la Carta Magna de 1993. El problema de fondo de este proyecto es la inconstitucionalidad de modificar un texto constitucional que no está vigente bajo un procedimiento de reforma enmendado de la Constitución actual, desconociendo la naturaleza y los rasgos del poder constituyente y del poder constituyente constituido. Por eso,

1 Doctor en Derecho por la Universidad de Navarra, profesor de Derecho Constitucional e Integración por la Universidad de Piura, y titular de la Cátedra Jean Monnet de la Comisión Europea. 
antes de abordar el análisis del proyecto, es necesario revisar estos conceptos para formar una opinión respecto a su contenido.

\section{Los rasgos del poder constituyente}

En primer lugar, como sabemos, la Nación conserva un poder distinto al de los poderes constituidos por una Carta Magna (las funciones legislativa, ejecutiva y judicial), como es la facultad de cambiar y dar una nueva Constitución. No obstante, este poder constituyente no puede ejercerse por la Nación en conjunto porque es imposible; por ello, la necesidad de convocar a representantes reunidos en una asamblea para formar un poder superior y diferente de los poderes constituidos. Esta particularidad suele propiciar momentos de crispación política entre la asamblea y el Congreso, producto del celo parlamentario y la doble representatividad reinante en un mismo momento político.

Por tratarse de un poder inherente a la Nación, los ciudadanos tendrán que aprobar o desaprobar el nuevo texto constitucional mediante una consulta popular (referéndum); sin embargo, debe haber tiempo suficiente para organizar una adecuada campaña de difusión y discusión nacional.

Todos los miembros de esa asamblea están vinculados por un mismo compromiso: elaborar un nuevo texto constitucional. Por ello, sus facultades se encuentran condicionadas por las siguientes características (Pereira, 2006, pp. 70-71) $)^{2}$ :

1. Coyuntural: porque se ejerce en un determinado momento, preferentemente como salida a un régimen de facto e inicio de una transición democrática. Una vez terminado el encargo de elaborar un nuevo texto constitucional —que deberá ser aprobado por una consulta popular-, su labor concluye y deberá disolverse, ya que se invoca en situaciones muy concretas y bajo especiales circunstancias políticas.

2. Inapelable: lo cual no significa que sea un poder ilimitado, ya que sobre él solo se encuentran el Derecho natural y las reglas elementales del Derecho internacional público (conocidas como las normas de ius

2 Sobre las caracteristicas del poder constituyente, véase Pereira (2006). cogens) para frenar disposiciones que no sean conformes con la teoría constitucional.

3. Fáctico: por tratarse de un poder que puede ir más allá de lo normado anteriormente. Es decir, la acción del poder constituyente suele acarrear una quiebra al Derecho positivo vigente.

4. Eficaz: cuando la creación de un nuevo orden jurídico y político se impone a pesar de los fundamentos de la oposición que no goza de la mayoría.

Luego de exponer estas características podemos comprender que cuanto menos se ejerza el poder constituyente, mejor. Lo contrario supondría una situación constitucional que puede derivar en inestable. Países como Francia, España y Portugal, sin contar Perú, han recurrido a asambleas constituyentes en muchas oportunidades durante los siglos XIX y Xx, mientras que en el Reino Unido, Estados Unidos y Bélgica han sido convocadas muy pocas veces, y, en consecuencia, han obtenido resultados de gran duración que resaltan a la vista.

\section{El procedimiento de enmienda constitucional}

Como no siempre es prudente convocar a una asamblea constituyente en razón a determinadas circunstancias políticas, la teoría constitucional tiene previsto otro mecanismo: la reforma o enmienda. No significa un camino de segundo orden, sino que está prevista cuando los cambios constitucionales se hacen necesarios durante el mandato de gobiernos democráticamente elegidos, es decir, cuando la necesidad de reformar la Constitución se manifiesta dentro de un régimen democrático, con autoridades y representantes libremente elegidos. Para estos casos, la teoría constitucional tiene previsto el llamado "poder constituyente constituido", que supone el establecimiento de un órgano $\mathrm{y}$ un procedimiento por cada Constitución para su cambio. De esta manera, la reforma constitucional se planteará como una enmienda formal que discurrirá por los causes ya previstos de la misma Constitución que va a ser modificada.

Los principales caracteres del poder constituyente constituido son los siguientes (Pereira, 2006, p. 72): 
1. Goza de legitimidad, pues se trata de un procedimiento $\mathrm{y}$ órgano previsto especialmente. Por eso es limitable y debe ajustarse a lo previsto por la Constitución.

2. Respeta el Derecho existente, pues solo buscará corregir aquellas instituciones que no cumplen con la finalidad de la Constitución. Frena el poder político para asegurar toda una esfera de derechos y libertades al ciudadano.

3. No es anterior a todo el Derecho por fundarse en la Constitución, pero puede reformarla.

4. Es limitable por definición y se encuentra sujeto a las condiciones y procedimientos que fije la propia Constitución que se ha de reformar.

El concepto del poder constituyente constituido se relaciona directamente con la reforma constitucional; es decir, el poder de enmendar la Constitución es por sí mismo constituyente, pero, por estar prevista su existencia y procedimiento en la propia Constitución, carece de un poder inapelable. De esta manera, así como el poder constituyente es un acto de puro poder que conserva la Nación, el poder constituido sería más bien un acto de potestad, un poder socialmente reconocido.

Ladoctrinanos dicequelareformaconstitucional es una técnica, un procedimiento. Pero ¿es solo una técnica, solo un procedimiento? Parecería que sí. No obstante, si nos damos cuenta, el Derecho Constitucional estaría poco seguro si los procedimientos de reforma no tuviesen ciertos límites para su ejercicio, como los tienen otras instituciones previstas en la propia Constitución (los límites a la Presidencia de la República, al procedimiento legislativo y los principios del debido proceso). Por eso, antes que nada, conviene que nos preguntemos por qué existe un procedimiento de reforma constitucional. Son varias las razones que motivaron su creación y algunas de ellas son de sentido común:

1. Los constituyentes no son dioses: aún en el caso de que la Asamblea Constituyente esté integrada por un conjunto de juristas y políticos notables, estos no gozan de un principio de infalibilidad al momento de elaborar una Constitución. Todo lo contrario: se pueden equivocar por acción (por establecer en la Carta Magna alguna disposición que, en vez de concentrar, dispersa el poder) o por omisión (cuando existen vacíos que dejaron al consenso de los políticos y no a la interpretación judicial, con sus inmediatas consecuencias para la separación de poderes).

2. Es jurídica y políticamente correcto que la Constitución tuviese previsto su propio procedimiento de reforma; es decir, era necesario que los parlamentarios tuviesen unas reglas preestablecidas por los propios constituyentes y no esperar a buscar acuerdos dentro del Parlamento y sus mayorías ocasionales.

3. Para Estados sin tradición constitucional es conveniente establecer un procedimiento lo suficientemente riguroso para evitar unas reformas inmaduras, un propósito que no se ha cumplido del todo en las constitucionales iberoamericanas.

La Constitución peruana, al igual que la mayoría en el mundo, tiene un especial procedimiento de reforma que dificulta su rápida enmienda ${ }^{3}$. Por ese motivo, de acuerdo con los argumentos de Bryce (1988), nuestras constituciones pertenecen al grupo de las rígidas ${ }^{4}$. En cualquier caso, el mismo autor considera que la estabilidad de cualquier Constitución no dependerá de su procedimiento de reforma, sino de «las fuerzas sociales y económicas que la apoyan y sostienen» (ibid., p. 28).En otras palabras, volvemos a la idea de un pacto de límites en el ejercicio del poder. Como las Constituciones rígidas carecen de un procedimiento único, veamos de cerca el grado de complejidad de la reforma en la Constitución peruana de 1993.

\section{El procedimiento de aprobación de la reforma constitucional}

Con relación a este tema, el Tribunal Constitucional nos dice:

El carácter de poder constituido de la reforma constitucional viene asociado a la presencia de determinados límites en su ejercicio. Quiere ello

3 El procedimiento de reforma constitucional se estudiará más adelante en este capítulo.

$4 \mathrm{El}$ mismo autor considera que las constituciones clásicas son más "flexibles" debido a que poseen una mayor elasticidad a los cambios sociales y políticos, adaptándose permanentemente, sin correr el riesgo de perder sus principales características. 
decir que, para que una reforma pueda considerarse válidamente realizada, debe respetar los criterios que la Constitución, por voluntad del Poder Constituyente, expresamente estableció; criterios que, por lo general, aunque no exclusivamente, se encuentran relacionados a la presencia de mayorías calificadas en el procedimiento de su aprobación o a una eventual ratificación directa por parte del pueblo (Exp. 0014-2002AI/TC)..

El artículo $206 .^{\circ}$ de la Constitución peruana establece dos procedimientos para que la enmiende el Parlamento. El primero de ellos establece que la ley de reforma debe ser aprobada por una mayoría absoluta — sesenta y un parlamentarios - para luego ser ratificada por referéndum. El segundo procedimiento consiste en someter la ley de reforma "a dos legislaturas ordinarias sucesivas con una votación favorable, en cada caso, superior a los dos tercios del número legal de congresistas", es decir, a ochenta miembros.

El procedimiento de reforma en la Constitución peruana es propio de un estado unitario y por ello adolece de ciertos riesgos. No establece los casos en que será necesario aprobar una reforma constitucional bajo el procedimiento de consulta popular, lo cual puede generar cierta polémica y cuestionar la legitimidad de optar por uno o u otro procedimiento, dado que se prestará al cálculo político. Desde ese punto de vista, consideramos que toda propuesta de enmienda relativa a la descentralización o una reforma total de la Constitución deberá ser aprobada mediante una consulta popular.

El procedimiento de reforma, por su escasa aplicación, no merece mayor detenimiento porque, en vez de periódicas enmiendas constitucionales, hemos tenido sucesivos cambios de constituciones en la historia republicana, los cuales marcaron el inicio y fin de las interrupciones de los periodos democráticos. Por eso, bajo cualquier procedimiento de reforma, debemos tener en cuenta que, si resulta demasiado simple, la Constitución quedará en manos de mayorías parlamentarias cambiantes. En tanto, si dificultamos el procedimiento sobre la base de requisitos y mayorías, los cambios serán efectuados o bien solapadamente por medio de una mutación constitucional sin afectar la estabilidad política, o de manera violenta por una revolución o golpe de Estado, afectando así las reglas del Estado de Derecho.

\section{Los limites a la reforma constitucional}

El poder de reforma constitucional, también conocido como poder constituyente constituido, está investido de ciertos criterios a tener en cuenta para ejercerlo sin violar las disposiciones constitucionales. Dichos procedimientos se convierten en los llamados "límites formales". El Tribunal Constitucional nos dice que el poder de reforma constitucional:
[...] a diferencia de lo que ocurre con el Poder Constituyente, es un poder limitado. Mientras que el poder creador carece de referentes objetivos y en el último de los casos, solo puede condicionarse por las valoraciones sociales dominantes (no sería admisible un Constituyente que destruya la voluntad del pueblo), el poder creado para reformar tiene en sí mismo diversas restricciones, todas ellas nacidas de la Constitución (Exp. $N{ }^{\circ}{ }^{\circ}$ 0014-2002-AI/TC).

La Constitución peruana no establece claramente límites materiales al procedimiento de reforma ${ }^{5}$; sin embargo, se pueden descubrir entre sus disposiciones algunos de estos. En ese sentido, el segundo párrafo del artículo $32 .^{\circ}$ nos dice que «[...] no pueden someterse a referéndum la supresión o la disminución de los derechos fundamentales de la persona [...]» (Bernales, 1996) ${ }^{6}$. Consideramos que este es un límite por tratarse de la afectación de los derechos fundamentales. Tampoco es posible la afectación de los derechos mediante una reforma que resulte de la aprobación por mayoría calificada de dos legislaturas ordinarias del Congreso. En ese mismo sentido, el Tribunal Constitucional nos dice que «la prohibición a la que se alude en el segundo párrafo del artículo

5 Con relación al significado de los limites materiales, el Tribunal Constitucional peruano sostiene que ellos hacen referencia a los contenidos de la Constitución, es decir, "con ellos no se indica la presencia de condicionamientos de tipo procedimental, sino algo mucho más trascendente; esto es, la presencia de parámetros de identidad o esencia constitucional, inmunes a toda posibilidad de reforma" (Exp. N. ${ }^{\circ}$ 0014-2002-AI/TC).

6 En ese sentido, Bernales sostiene que se debió relacionar el artículo $32 .^{\circ}$ con el procedimiento de reforma constitucional. Véase además el trabajo de Dumet (2002). El proceso de reforma de la Constitución de 1993 y sus límites (pp. 63-66). 
32 de la Constitución, en principio, no está dirigida a limitar la competencia del Congreso de la República para realizar la reforma constitucional, sino a la posibilidad de que tales materias puedan someterse a referéndum» (Exp. N. ${ }^{\circ}$ 0014-2002-AI/TC, fundamento jurídico 90). Debemos añadir que la interpretación de esta disposición no solo se circunscribe a los derechos fundamentales reconocidos en el segundo artículo constitucional, sino también a los no escritos formalmente, de acuerdo a la cláusula de apertura a los derechos, recogida en el artículo $3 .^{\circ}$ de la Carta de 1993 , la cual explicaremos más adelante.

Sobre los límites a las enmiendas constitucionales, el máximo intérprete de la Constitución nos dice lo siguiente:

\section{[...] si a través de una ley de reforma constitucional se vulnera la esencia misma de la Constitución, y siendo el Tribunal Constitucional, tal como lo señala explícitamente el artículo 201 de la propia Constitución, el órgano de control de la Constitución, se encuentra legitimado para intervenir excepcionalmente como un ente competente para analizar la norma constitucional impugnada, pero única y exclusivamente sobre la base del 'contenido fundamental' protegido implícitamente en la Constitución (Exp. $N .^{\circ}$ 0014-2002-AI/TC, fundamento jurídico 4).}

En el derecho comparado observamos otros límites al procedimiento de reforma. Por ejemplo, la Constitución alemana no permite enmiendas que afecten su división territorial y tampoco al principio de cooperación entre los Länder ${ }^{7}$. Asimismo, las constituciones francesas e italiana impiden sustituir la forma republicana de gobierno ${ }^{8}$. La Constitución española, en tanto, dispone que no podrá iniciarse la reforma constitucional en tiempo de guerra o durante la vigencia de alguno de los estados de excepción ${ }^{9}$. Este constituye un límite a la reforma que, en la práctica, dudamos que el Parlamento español considere oportuno proponer durante una excepcional coyuntura política.

7 Véase el artículo 79.3 de la Ley Fundamental de Bonn.

8 Véase el artículo 89 de la Constitución francesa de 1958 y el artículo $139 .^{\circ}$ de la Constitución italiana de 1947.

9 Véase el artículo $169 .^{\circ}$ de la Constitución española de 1978

\section{LOS ANTECEDENTES HISTÓRICOS Y CONSTITUCIONALES DE LA LEY DE REFORMA CONSTITUCIONAL N. ${ }^{\circ}$ 2001/2012-IC.}

La discusión en torno a la situación jurídicopolítica y futuro de la Carta de 1993 fue tratada por la Comisión de Estudio de las Bases de la Reforma Constitucional del Perú, la cual consideró tres caminos: primero, declarar la nulidad de la Carta de 1993 para retornar a la vigencia de la Constitución de 1979; segundo, reformar la Constitución de 1979, adaptándola a los tiempos modernos y reconociendo instituciones novedosas y que funcionan -como la Defensoría del Pueblo-, al igual que los tratados sobre derechos humanos y demás normas que garanticen la estabilidad política y jurídica. La tercera consiste en convocar a un referéndum para que el pueblo decida volver a la Carta de 1979 o encomendar la elaboración de una nueva Constitución.

Las reacciones al informe no fueron inmediatas, pero tuvo dos claros efectos, uno político y otro jurídico. El primero fue el discurso presidencial del Dr. Alejandro Toledo Manrique durante su mensaje anual de Fiestas Patrias (28 de julio de 2003). En él recordó la necesidad de que el Congreso de la República tome una posición respecto a la sentencia declarada improcedente por el Tribunal Constitucional y que pretendía dejar sin efecto la Carta de 1993 mediante una acción de inconstitucionalidad (Exp. N. ${ }^{\circ} 014-$ 2003-AI/TC $)^{10}$.

El Tribunal Constitucional resolvió en la sentencia que al Congreso le correspondía la responsabilidad de consolidar de manera definitiva el proceso de institucionalización democrática, así como la decisión de optar políticamente por el marco constitucional más conveniente. Por ello, invocó al Congreso para que adopte las medidas concretas y lo exhortó para que opte por alguna de las posiciones planteadas por la Comisión de Estudio de las Bases de la Reforma Constitucional antes del vencimiento del mandato parlamentario, en julio de $2006^{11}$. Con la presentación del

10 La acción de inconstitucional fue interpuesta por Alberto Borea Odría y más de cinco mil ciudadanos contra la Constitución peruana (denominada "documento"), promulgada el 29 de diciembre de 1993, cuya validez fue objetada por los recurrentes.

11 ElTribunal Constitucional culmina su resolución declarando improcedente la demanda de inconstitucionalidad contra la 
proyecto de ley de reforma N. ${ }^{\circ}$ 2001/2012 del artículo 206. ${ }^{\circ}$ de la Constitución de 1993 se esperaba establecer un procedimiento para su enmienda total tomando como base la Constitución de 1979. Fue publicado en el diario oficial El Peruano el sábado 23 de marzo de 2013. En el proyecto se estableció un nuevo y polémico procedimiento de reforma total a la Constitución de 1993, que analizaremos punto por punto:

\section{Se modifica el procedimiento de reforma constitucional}

Nos preguntamos si es viable modificar el procedimiento de reforma que estableció el Constituyente. Desde un punto de vista formal puede ser posible, pero en lo material sería burlar la finalidad de una Constitución rígida, es decir, sería evitar la flexibilización de los mecanismos de enmienda constitucional y se atentaría contra la seguridad jurídica. Como sabemos, una Constitución rígida se caracteriza por tener un complejo procedimiento de reforma constitucional y demanda un gran consenso parlamentario para evitar enmiendas inmaduras al texto de la Constitución, a diferencia del modelo británico, que es flexible y puede enmendarse por una ley ordinaria del Parlamento de Westminster, en razón al peso histórico, social y político de sus arraigadas tradiciones -al punto en que la única Constitución flexible en el derecho comparado es, precisamente, la del Reino Unido-.

El artículo $206 .^{\circ}$ de la Constitución de 1993 no imposibilita su reforma total. Si lo concordamos con el inciso (1) del artículo $32 .^{\circ}$, podemos observar que la Carta de 1993 permite que puedan ser sometidas a referéndum "la reforma total y parcial de la Constitución". En ese sentido, proponer una enmienda precisamente al artículo que regula el procedimiento de reforma constitucional no es muy saludable debido a que, si bien la Carta de 1993 no lo dice expresamente, nos encontramos con un núcleo duro de reforma implícito en toda Constitución; es decir, estaríamos afectando una norma que opera como una cláusula de garantía al texto constitucional con procedimiento que demanda gran consenso político para establecer

Constitución Política del Perú de 1993. Además, exhorta al Congreso de la República para que proceda, conforme a lo señalado, y disponga la notificación a las partes, así como su publicación en el diario oficial El Peruano y la devolución de los actuados. las reformas institucionales Además, estaría convirtiendo peligrosamente a una Constitución de naturaleza y tradición rígidas en una flexible, cuando no es parte de nuestra realidad política, jurídica ni cultural en la historia de los textos constitucionales peruanos.

El inciso (e) del mismo proyecto de ley establece que «consolidado el texto de las reformas a la Constitución de 1979, se declarará la nulidad de la denominada Constitución Política del Perú de 1993, con lo cual el propósito de la reforma difiere del título del proyecto, que dice establecer un procedimiento para la reforma total de la actual Constitución, tomando como base para ello el texto de la Constitución de 1979». En la realidad, se trataría de retornar a la Constitución anterior - no rige hace veinte años - para incorporar a las instituciones que se aconsejen de la Carta Magna actual y luego, una vez culminada la transferencia, declarar su respectiva nulidad.

Si ese es el real sentido del proyecto, nos preguntamos si el procedimiento de reforma de la Constitución de 1993 puede aprobarse para modificar una Constitución que ha dejado de regir (1979) y, posteriormente, declarar nula la de 1993, que se ha deseado modificar gracias a una flexibilización de su propio procedimiento de reforma. En resumen, el proyecto revela el propósito de retornar a la Constitución de 1979, agregar las instituciones de la Carta Magna de 1993 que la mayoría parlamentaria considere oportunas, aprobarlas con solo 65 votos y luego declarar la nulidad de la actual Constitución.

\section{EL CONTENIDO DEL PROYECTO DE LEY DE REFORMA}

El proyecto de ley de reforma establece unos planteamientos iniciales y límites que el Congreso deberá tener presente. El inciso (b) de la propuesta de modificación del artículo $206 .^{\circ}$ establece que el preámbulo constitucional será respetado en su integridad pero que podría ser ampliado en la medida en que afirmen los principios y valores nacionales. Así, es probable que el preámbulo original termine siendo el encabezado del que perteneciera a la Constitución de 1979 precisamente porque evocaba los principios que inspiran a la Nación. El inciso (c) del mismo proyecto dispone como ejemplo que se deberán incorporar al texto las 
instituciones que fueron creadas en 1993, como la Defensoría del Pueblo y otras que ayuden en el desarrollo democrático, social y económico del país. No obstante, nos preguntamos cómo se pueden incorporar al texto constitucional las instituciones que forman parte de la misma Constitución. Nos referimos precisamente a la Defensoría del Pueblo, que fue reconocida en la Carta de 1993. Al respecto, pensamos que el propósito es precisamente inverso: que la institución de la Defensoría del Pueblo se desea trasladar a la Constitución de 1979, cuando el texto del proyecto de ley se aprobaría para, teóricamente, reformar la Constitución de 1993 y no la Carta Magna anterior, que carece de vigencia.

En el inciso (d) del mismo proyecto se establece que el Congreso deberá establecer medidas transitorias para convalidar los efectos de los actos jurídicos que los particulares y entes públicos hayan desarrollado de acuerdo al texto de la Constitución de 1993, en los que no se hubiesen cometido actos ilícitos y violatorios de los derechos humanos. Dispone, además, que los actos desarrollados durante el proceso de reforma serán estimados jurídicamente conforme a dichas disposiciones. Sobre el particular, nos preguntamos cuál será el futuro de las sentencias del Tribunal Constitucional y de sus precedentes vinculantes. Si la redacción del proyecto parece indicar que la Constitución que se desea reformar es la de 1979, además de la inconstitucionalidad de dicha disposición, se estaría afectando la seguridad jurídica que debe brindar el Estado peruano, especialmente porque existen notables diferencias entre ambas constituciones en lo referente a las disposiciones de la llamada Constitución económica. En su momento, la Constitución de 1979 permitía la participación del Estado en la actividad económica, mientras que la Carta de 1993 establece en su artículo 60. ${ }^{\circ}$ que, solo por ley expresa, el Estado peruano puede realizar subsidiariamente actividad empresarial.

Finalmente, el inciso (i) del proyecto establece que el Congreso de la República podría incorporar la reelección presidencial inmediata, desconocer derechos fundamentales y no realizar cambios al régimen republicano, democrático ni representativo. Salvo la primera prohibición - la cual no creemos que llegará a aprobarse si fuese planteada-, las demás son obviedades si lo que se pretende es mantener un orden constitucional $\mathrm{y}$ no instaurar una dictadura.

\section{El orden de los factores si altera el producto}

A diferencia de lo que ocurre con las ciencias exactas, la estrategia para reformar totalmente la Constitución de 1993 no puede realizarse desde la Carta Magna de 1979, incorporando lo que se considere mejor de la actual Constitución, sino desde la propia Norma Fundamental de 1993, precisamente porque se desea reformar su propio procedimiento de enmienda, reconocido en el artículo $206 .^{\circ}$. En consecuencia, el proceso de reforma debe efectuarse desde la Constitución vigente (1993), a la cual se le pueden incorporar instituciones o modificar algunas en función a lo establecido por la Carta de 1979, no al revés. Por otro lado, el Congreso carece de poderes constituyentes para declarar nulo el texto constitucional, toda vez que solo tiene competencia para enmendarla total o parcialmente, pues únicamente puede obrar como un poder constituyente constituido; es decir, para el caso concreto de una reforma constitucional, el poder constituyente constituido es limitable por definición y se encuentra sujeto a las condiciones y procedimientos que fije la propia Constitución que se ha de reformar.

\section{La opción de convocar una nueva Asamblea Constituyente}

El proyecto de ley que analizamos establece un plazo fijo de un año a partir de la promulgación de la norma para que el Congreso cumpla con realizar el procedimiento de reforma constitucional. Asimismo, el inciso (h) añade que el presidente de la República tendrá siete días para promulgar el texto de reforma a la Constitución de 1979, cuando en la realidad la Carta Magna a reformar es la Constitución vigente (1993). Este aspecto es inconstitucional, pues no se puede modificar la Constitución de 1979 dado que no tiene vigencia. Antes se debería retornar a ella formalmente para luego plantear las reformas de acuerdo a su propio procedimiento.

El proyecto añade en su último inciso (j) que si concluye el plazo de un año para la reforma de la Constitución de 1979 (el legislador vuelve a cometer sistemáticamente el error en mención, pues debería referirse a la Carta de 1993), el presidente de la República convocará una Asamblea Constituyente derivada y especial de cien miembros elegidos por sufragio único 
para que en el mismo plazo de un año procedan a enmendar la Constitución conforme dispone el contenido del mismo proyecto de ley. Dispone, además, que el Congreso quedaría en suspenso en su facultad de enmendar la Constitución. Sobre el inciso (j) del proyecto, solo dos cuestiones adicionales: en primer lugar, la convocatoria del poder constituyente no está llamada a reformar una Constitución, sino a elaborar un nuevo texto constitucional, el cual debería someterse a consulta popular para su aprobación; en segundo lugar, y como consecuencia de lo anterior, el proyecto confunde las funciones del poder constituyente, y la convocatoria a una asamblea para elaborar una nueva Constitución con la real facultad del Congreso de ser el órgano previsto para realizar una reforma constitucional (poder constituyente constituido).

Los detractores de la Constitución de 1993 recuerdan que la Carta Magna de 1979 disponía que no pierde su validez y vigencia por actos de fuerza, o los que no se sustentan en la soberanía del pueblo ${ }^{12}$. Si bien, desde un punto de vista constitucional, retornar a la Carta de 1979 sería lo consecuente de acuerdo a la historia, política y el Derecho Constitucional, también es cierto que no ha existido consenso parlamentario para tomar esa decisión. Durante el tiempo de indecisión política, la Constitución de 1993 ha adquirido una legitimidad de ejercicio gracias a las elecciones periódicas de las instituciones políticas (Gobierno, Parlamento, regiones, municipios, diversas consultas populares, etc.), continuidad democrática y consolidación como la Carta Magna peruana con el mayor desarrollo jurisprudencial en la historia de la República, lo que equivale a decir que se trata de una Constitución viviente.

\section{EL PROYECTO DE LEY N. ${ }^{\circ}$ 267/2016-CR QUE PROPONE INCORPORAR DE MODO EXPRESO EL RECONOCIMIENTO DE UN ESTADO LAICO}

Se trata de un proyecto de reforma presentado por el grupo parlamentario Frente Amplio

$12 \mathrm{El}$ artículo $307 .^{\circ}$ de la Carta de 1979 disponía lo siguiente: "Esta Constitución no pierde su vigencia ni deja de observarse por acto de fuerza o cuando fuere derogada por cualquier otro medio distinto del que ella misma dispone. En esta eventualidad todo ciudadano investido o no de autoridad tiene el deber de colaborar en el restablecimiento de su efectiva vigencia". por Justicia, Vida y Libertad, que propone modificar el artículo $50 .^{\circ}$ de la Constitución Política del Perú a efectos de incorporar de modo expreso el reconocimiento de un Estado laico. El contenido del proyecto se describe a continuación:

\section{La propuesta de reforma constitucional}

Un Estado laico es aquella comunidad política en la que existe independencia y autonomía con las diferentes iglesias, lo cual implica su neutralidad en materia religiosa; es decir, las creencias religiosas no influyen sobre la política nacional. En cambio, se entiende por un Estado confesional aquel en que adopta oficialmente una religión en su Constitución política.

Si el Perú es o no un Estado laico, merece un doble análisis. Por un lado, se debe ahondar en la concreta regulación de los derechos y libertades fundamentales en la Constitución de 1993; por otro, se debe determinar también qué debemos entender por laico, ya que este concepto nos puede derivar a planteamientos políticos tan diversos entre sí como la llamada laicidad y el laicismo.

Por laicismo debemos comprender el diseño de un Estado como ajeno a la identificación con un credo religioso. El centro de apoyo del laicismo puede comprenderse como una no contaminación marcada con signos de fundamentalismo (Ollero, 2015, p. 17), con abierta contienda de las fuerzas políticas con representación parlamentaria o en el Gobierno, más que como la neutralidad que las disposiciones constitucionales le confieren al Estado sobre las distintas confesiones religiosas. En ese sentido, el laicismo promueve una tajante separación que reenvía toda convicción religiosa al ámbito íntimo de la conciencia individual, que resulta más "neutralizadora" que solo neutra ante su proyección al ámbito público.

La versión más extrema del laicismo nos llevaría a manifestar una posible discriminación en razón de la religión; en consecuencia, determinadas propuestas de políticas públicas podrían ser descalificadas como confesionales por el hecho de haber encontrado acogida en la doctrina social, o moral, de alguna de las religiones libremente practicadas por los ciudadanos (ibid. p. 18). 
Si no se tienen claras las reales dimensiones del concepto, la propuesta de reforma constitucional que declare al Estado peruano expresamente como laico corre el riesgo de poder convertirse, en la práctica política, en lo más opuesto a la laicidad cuando se pretende encorsetar determinados problemas civiles. La preocupación por ellos derivaría inevitablemente en una indebida injerencia de lo sagrado o religioso en las políticas públicas. Se trata de una desviación que podría estar ocurriendo en la opinión pública peruana, cuando la ciudadanía plantea la defensa de la vida humana prenatal, la libre elección de centros escolares, el contenido de los planes educativos o la debida protección jurídica a la natural institución del matrimonio monogámico y heterosexual.

De acuerdo al problema descrito en el párrafo anterior, para preservar un abierto pluralismo es esencial que aceptemos una doble realidad: En primer lugar, que no puede existir una propuesta de política pública que a su vez no se fundamente, directa o indirectamente, en alguna convicción; en segundo lugar, que ha de considerarse como irrelevante que dicha convicción tenga o no algún parentesco de tipo religioso, pues todos los seres humanos tenemos convicciones que echan raíces desde temprana formación (ibid., pp. 25-26).

En el marco de un Estado Constitucional de derecho, la debida interpretación judicial de la Carta de 1993 reconoce al Estado peruano como laico. En ese sentido, consideramos innecesario el proyecto de ley de reforma presentado. Nuestros argumentos son los siguientes:

\section{La interpretación judicial de la Constitución comprende a la comunidad politica peruana como un Estado que reconoce y no discrimina las confesiones religiosas.}

La interpretación de las disposiciones constitucionales por parte del Tribunal Constitucional peruano configura el reconocimiento de un Estado laico. La libertad religiosa está garantizada como derecho fundamental, así como el ejercicio de cualquier confesión, siempre que no afecte el orden público o implique realizar actividades tipificadas como delito.
La propuesta de reforma constitucional que tiene la pretensión de declarar formalmente laico al Estado peruano no añade ni resta a la interpretación que reiterada jurisprudencia del Tribunal Constitucional ha venido dictando sobre las relaciones Iglesia-Estado. Las referencias a Dios, a la creación o a una confesión religiosa concreta (la Iglesia católica) se fundamentan no como una mejor posición de esta confesión religiosa, sino a consecuencia de tratarse de una de las tradiciones culturales fundacionales del Estado peruano para la formación de valores de la sociedad, presente en la historia de la Conquista, Emancipación y vida republicana, destacando el reconocimiento de un principio colaborativo con ella y todas las iglesias.

La reforma propuesta no parece necesaria gracias a la interpretación realizada por el Tribunal Constitucional, lo cual despeja cualquier duda sobre la laicidad del Estado peruano. La naturaleza de las enmiendas constitucionales es añadir, retirar o realizar una o un conjunto de precisiones con la finalidad de lograr la claridad necesaria para su debida aplicación. No obstante, si el máximo intérprete de la Constitución ha realizado la tarea de aclarar los conceptos y alcances de las disposiciones afectadas por una ley de reforma constitucional, consideramos ocioso realizarla dado que, gracias a la interpretación judicial de la Constitución, se ha producido una colaboración entre las funciones del poder.

Las interpretaciones que realiza el Tribunal Constitucional, las reglas jurídicas producidas por sus precedentes vinculantes y la creación de normas constitucionales adscriptas, también forman parte sustancial de la Carta de 1993 para su debida comprensión y alcances en un Estado Constitucional de Derecho. Por eso, no es necesaria una reforma constitucional concreta sobre un tema aclarado por el mismo órgano de control de la constitucionalidad.

\section{EL PROYECTO DE LEY 1740/2017- CR QUE PROPONE RESTITUIR EL SISTEMA BICAMERAL}

El Parlamento unicameral fue aprobado por la mayoría de la Asamblea Constituyente que redactó la Carta de 1993. El texto constitucional reforzó a la Comisión Permanente para que asuma algunas de las competencias que tenía el 
Senado de la Constitución de 1979. En efecto, la Carta de 1993 transfiere a la comisión determinadas atribuciones del Senado y de la Cámara de Diputados, establecidas en la Constitución de $1979^{13}$. De esta manera, la Comisión Permanente se convirtió en una cámara acusadora en el procedimiento de antejuicio constitucional, establecido en el artículo 98. ${ }^{\circ}$ de la Constitución de $1993^{14}$. Pero, además, esta casi puede sustituir al Congreso en sus atribuciones naturales, como es en el ejercicio de la facultad legislativa.

La decisión de la Asamblea Constituyente de dotar al Parlamento peruano de una sola cámara tuvo el propósito de favorecer al Ejecutivo en su tarea de gobierno, siempre y cuando cumpla mayoría. Por otro lado, una Comisión Permanente de estas características hace que el centro del debate político no sea el Pleno, sino una cámara reducida. Por eso, la doctrina denomina a la Comisión Permanente como un mini-Parlamento, pues su finalidad explícita en la Constitución y el reglamento parlamentario es reducir, en lo posible, el debate político, la fiscalización y la producción legislativa a solo treinta parlamentarios, un número ideal para el partido que ostente la mayoría, sea del Ejecutivo o de la oposición. Al parecer, todo está dispuesto para que así ocurra cuando la Comisión Permanente no cuente con un reglamento propio, sino que aplique el del Congreso ${ }^{15}$. Es decir, en la práctica, la Comisión Permanente podría sustituir al Pleno, como si se tratara de un Parlamento en miniatura, especialmente cuando el Ejecutivo cuenta con mayoría absoluta.

El proyecto de ley 1740/2017-CR, presentado por el grupo parlamentario Célula Parlamentaria Aprista, propone modificar la Constitución para restituir el sistema bicameral en la estructura del Congreso de la República. Una de las reformas urgentes al sistema político es el retorno a la bicameralidad del Congreso, pues, el Parlamento actualmente se encuentra desbordado de trabajo legislativo pendiente a debatir, mientras se ocupa en paralelo de su labor fiscalizadora fruto del ejercicio de la política doméstica.

13 Entre ellas mencionamos, por ejemplo, la designación del contralor general, la ratificación del presidente del Banco Central y del Superintendente de Banca y Seguros. Véanse los artículos 146, 151 y 155 de la Constitución peruana de 1979, respectivamente.

14 En la Constitución peruana de 1979, la Cámara de Diputados iniciaba el procedimiento de acusación constitucional. Véase el artículo 183 de dicha Constitución. 15 Véase el artículo del $44 .^{\circ}$ del Reglamento del Congreso.
Si bien la necesidad de debatir y aprobar una reforma constitucional que retorne la segunda cámara es un tema poco popular $-\mathrm{y}$, para la mayoría de ciudadanos, menos prioritario que otros asuntos a tratar en el Congresodebemos destacar la dimensión regional y balance que aportaría una Cámara de Senadores en nuestro sistema político. En primer lugar, de acuerdo al proyecto, el Senado se convertiría en una Cámara Regional, pues su criterio de elección sería territorial bajo un principio de igualdad (dos senadores por cada región), lo cual favorecería el debate y discusión de los temas regionales, dejando a la Cámara de Diputados los temas de "política doméstica", que son más mediáticos y del día a día de las relaciones entre el partido de gobierno con las bancadas de oposición.

Las funciones representativas, legislativas y de control, más la velocidad del tiempo y su administración, también afectan la agenda parlamentaria. Basta observar la página electrónica del Congreso para constatar que las citaciones al Pleno no son diarias: cuando se convocan, debe distribuirse el tiempo para debatir diversos proyectos de ley, la aprobación de alguna herramienta de control parlamentario (preguntas, interpelaciones, comisiones de investigación, etcétera) y los congresistas desde sus bancadas deben "ponerse en cola» para impulsar sus iniciativas y ponerlas al debate. Por eso, en este contexto, no es inusual el surgimiento de contrariedades en el Pleno, incluso entre miembros de un mismo partido.

El contenido del proyecto y su necesidad de un retorno al Senado busca descongestionar el Congreso para que en aquella se discutan los temas de Estado, el nombramiento de las altas autoridades y los temas de orden territorial (Cámara Alta) para que los diputados puedan ocupar mayor tiempo en los asuntos de control político que demandan una mayor atención mediática (Cámara Baja).

En ese sentido, no es la primera vez que se suscitan contrariedades en el Pleno por la distribución del tiempo y prioridad para debatir proyectos de ley, una clara señal de alerta para retornar al Senado y brindarle un pulmón adicional al Congreso. Otro aspecto importante a tener en cuenta es la necesidad de confiar al Senado la tarea del nombramiento del Contralor General de la República, los directores del Banco Central de Reserva, el 
defensor del Pueblo y los magistrados del Tribunal Constitucional. Al tratarse de una cámara que no participa de la investidura al presidente del Consejo de Ministros y que tampoco goza de la facultad de interpelación, invitaciones, censura y rechazo de la cuestión de confianza, posee un "clima político" de menor crispación $\mathrm{y}$, por tanto, es más estable para lograr consensos y tomar prontas decisiones de importancia para las regiones y el país. En el marco de la separación de funciones, el Senado está llamado a convertirse en un efectivo contrapeso al interior del Congreso, pues realizará una segunda revisión de los proyectos de ley gracias a su diferente composición parlamentaria.

\section{A MODO DE CONCLUSIÓN: EL ESTADO DE LOS EXPEDIENTES $X$}

La agenda parlamentaria no atendida por los medios de comunicación se concentra en una batería de reformas de alcance diverso; por un lado, su deseo de orientar la tradición histórica y cultural hacia una suerte de laicismo intolerante $y$, por otro, al intento de recomponer la organización parlamentaria con el retorno al bicameramelismo; en ambos casos, se trata de proyectos de ley de reforma que pueden terminar siendo nuevamente encarpetados, pues, no ha sido la primera y tampoco la última vez que las representaciones políticas que se han sucedido en los periodos democráticos de 2001-2006, 2006-2011, 2011-2016 y 2016-a la fecha, lo han intentado pero sin un verdadero propósito de diálogo y concertación, concretamente para el retorno del Senado que, como premio consuelo, terminó en una enmienda que aumentó el número de congresistas de 120 a 130 representantes; una reforma que no favorecieron los vínculos ciudadano-legislador, ni un contenido representativo distinto como el que propiciaría una segunda cámara; es decir, diputados elegidos por un criterio proporcional, un senado regional y electo por un criterio de igualdad en los territorios (dos representantes por región).

Los proyectos de reforma orientados a transformar las raíces históricas y culturales de la nación, mediante la suma oportuna y coyuntural de votos congresales, sólo producirían un cambio formal en el texto constitucional pero sin atender a la realidad, experiencia de vida y sentimiento de las mayorías de ciudadanos de formación judeocristiana; un conjunto de propuestas lejanas a una intención de sinceramiento de la sociedad sino más cercanas a validar una batería de normas posteriores que sean contrarias a los principios que han definido el contenido y fin de la persona humana y la sociedad como comunidad política.

Los proyectos de reforma constitucional archivados que carecen hoy en día del impulso y real apoyo político, definen las intenciones de nuestros representantes y juntos nos muestran una agenda de temas que hoy no parecen relevantes, pero que podrían tenerlo en futuro próximo si la composición irregular de un Congreso compuesto de representantes radicales, fruto de la indignación ciudadana por la corrupción, asumiera las riendas del legislativo y el gobierno, dispuesto para abrir el cajón de los expedientes X.

\section{FUENTES DE INFORMACIÓN}

\section{Fuentes bibliográficas}

Bernales Ballesteros, E. (1996). La Constitución peruana de 1993. Análisis comparado. Lima: CIEDLA.

Bryce, J. (1988). Constituciones flexibles y constituciones rígidas. Madrid: Centro de Estudios Constitucionales.

Dumet Delfín, D. (2002). El proceso de reforma de la Constitución de 1993 y sus límites. Revista de Derecho, volumen 3. Universidad de Piura.

Ollero Tassara, A. (2005). España, ¿Un estado laico? La libertad religiosa en perspectiva constitucional. Madrid: Thomson Civitas.

Pereira Menaut, A. (2006). Lecciones de teoría constitucional (, 3. ${ }^{a}$ edición). Madrid: Editorial Colex.

\section{Fuentes electrónicas}

Constitución Política del Perú. (1979). Recuperado del sitio de internet del Congreso de la República del Perú: http://www4.congreso. gob.pe/comisiones/1999/simplificacion/ const/1979.htm 
Constitución Política del Perú. (1993). Recuperado del sitio de internet del Congreso de la República del Perú: http:// www4.congreso.gob.pe/comisiones/1996/ constitucion/cons 1993.htm

Constitución Francesa. (1958). Recuperado del sitio de internet del Congreso de la República del Perú: http://www2.congreso. gob.pe/sicr/cendocbib/con_uibd.nsf/EC633 9DCF5122263052574BF0052EC89/\$FILE/ constitucionfrancesa.pdf

Constitución Italiana. (1947). Recuperado del sitio de internet Congreso de la República del Perú: http://www.derecho.uba.ar/ publicaciones/lye/revistas/34/la-constitucionitaliana-de-1947.pdf

Constitución Española. (1978). Recuperado del sitio de internet del Congreso de España: $\quad$ http://www.congreso.es/docu/ constituciones/1978/1978_cd.pdf

Expediente N. ${ }^{\circ}$ 0014-2002-AI/TC (26 de septiembre del 2002). Recuperado de internet del Tribunal Constitucional: https://tc.gob.pe/ jurisprudencia/2003/00014-2002-AI.pdf

Expediente N. ${ }^{\circ} 014-2003-\mathrm{AI} / \mathrm{TC}$ ( 22 de agosto del 2003). Extraído del sitio de internet del Tribunal Constitucional: https://tc.gob.pe/ jurisprudencia/2003/00014-2003-AI.pdf
Exp. N. ${ }^{\circ}$ 00050-2004-AI/TC (3 de junio de 2005). Extraído del sitio de internet del Tribunal Constitucional: http://www.tc.gob. pe/jurisprudencia/2005/00050-2004-AI\%20 00051-2004-AI\%2000004-2005-AI\%20 00007-2005-AI\%2000009-2005-AI.pdf

Proyecto de Ley N. ${ }^{\circ}$ 2001/2012-IC. Recuperado del sitio de internet:

http://revistas.pucp.edu.pe/index.php/ pensamientoconstitucional/article/ viewFile/8956/9364

Proyecto de Ley N. ${ }^{\circ} 1740 / 2017-C R$. Recuperado del sitio de internet del Congreso de la República del Perú:

http://www.leyes.congreso.gob.pe/ Documentos/2016 2021/Oficios/De Mociones/OFICIO-17̄40-2017-2018-ADP-MCR.pdf

Proyecto de Ley N. ${ }^{\circ}$ 267/2016-CR. Recuperado del sitio de internet del Congreso de la República del Perú:

http://www.congreso.gob.pe/index. php?K=263\&id=7187\#.WpGwGtFrzIU

Reglamento del Congreso de la República del Perú. Recuperado del sitio de internet del Congreso de la República del Perú: http://www.congreso.gob.pe/Docs/files/ reglamentodelcongreso.pdf 